\title{
Evaluation of the impact of crotonic acid addition to the mixture of bromoxynil with terbuthylazine and nicosulfuron in lowered doses on selected weed species control
}

\author{
Ocena wpływu dodatku kwasu krotonowego do mieszaniny bromoksynilu \\ z terbutylazyną oraz nikosulfuronu w dawkach obniżonych na zniszczenie \\ wybranych gatunków chwastów
}

\author{
Renata Kieloch*, Hanna Gołębiowska
}

\section{Summary}

In the pot experiments, the effect of crotonic acid on the efficacy of herbicides Kukugran $340 \mathrm{SE}$ (bromoxynil $90 \mathrm{~g} / \mathrm{I}+$ terbuthylazine $250 \mathrm{~g} / \mathrm{l}$ ) and Nikosar 060 OD (nicosulfuron $60 \mathrm{~g} / \mathrm{l}$ ) applied at doses reduced by 50, 80 and $90 \%$ was investigated. Control groups with single application of the investigated products were also included. Crotonic acid affected the efectiveness of herbicides differently, depending on the herbicide, its dose and weed species. Its effect on weed control was only observed for the lowest doses (reduced by 80 and $90 \%$ ). The addition of crotonic acid to spray solutions did not affect the effectiveness of the tested herbicides against Capsella bursa-pastoris. It improved the efficacy of the tested herbicides against Chenopodium album when reduced doses were used and the efficacy of Kukugran 340 SE against Matricaria inodora when the dose lowered by $90 \%$ was applied. Antagonism between crotonic acid and Nikosar 060 OD was detected when used against Viola arvensis, M. inodora and Amaranthus retroflexus. The tested doses of crotonic acid used in the mixtures showed similar efficacy.

Key words: herbicide, crotonic acid, reduced dose, mixture, weed control

\section{Streszczenie}

W doświadczeniach szklarniowych badano wpływ kwasu krotonowego na skuteczność herbicydów Kukugran 340 SE (bromoksynil $90 \mathrm{~g} / \mathrm{l}+$ terbutylazyna $250 \mathrm{~g} / \mathrm{l}$ ) i Nikosar $060 \mathrm{OD}$ (nikosulfuron $60 \mathrm{~g} / \mathrm{l}$ ) w dawkach obniżonych o 50, 80 i $90 \%$. Uwzględniono również obiekty z samodzielną aplikacją każdego ze środków. Kwas krotonowy w zróżnicowany sposób wpływał na efektywność herbicydów, w zależności od rodzaju środka, wysokości jego dawki oraz gatunku chwastu. Jego wpływ na herbicydy zaobserwowano tylko dla dawek najniższych, tj. obniżonych o 80 i 90\%. Dodatek kwasu krotonowego do cieczy opryskowych nie wpłynął na działanie badanych herbicydów w stosunku do Capsella bursa-pastoris, natomiast poprawił działanie badanych środków w dawkach najniższych w odniesieniu do Chenopodium album oraz środka Kukugran 340 SE w dawce obniżonej o 90\% w stosunku do Matricaria inodora. Działanie antagonistyczne mieszaniny kwasu krotonowego z herbicydem Nikosar 060 OD stwierdzono w przypadku Viola arvensis, M. inodora i Amaranthus retroflexus. Badane dawki kwasu krotonowego użytego w mieszaninach działały z podobnym skutkiem.

Słowa kluczowe: herbicyd, kwas krotonowy, zredukowana dawka, zniszczenie chwastów

Instytut Uprawy Nawożenia i Gleboznawstwa - Państwowy Instytut Badawczy

Zakład Herbologii i Technik Uprawy Roli

Orzechowa 61, 50-540 Wrocław

*corresponding author: r.kieloch@iung.wroclaw.pl

ORCID: 0000-0001-7411-1115 


\section{Wstęp / Introduction}

Ze względu na duże skażenie środowiska pestycydami dąży się do zmniejszenia ilości tych substancji wprowadzanych na pola uprawne w zabiegach ochrony roślin, wykorzystując w tym celu inne niż chemiczne metody regulacji zachwaszczenia, m.in. odpowiednią agrotechnikę. Poszukuje się również naturalnie występujących w roślinach i uwalnianych do środowiska substancji, które mogą działać fitotoksycznie na chwasty. Od kilkudziesięciu lat podejmowane są liczne prace nad wykorzystaniem potencjału allelopatycznego roślin do ochrony upraw przed agrofagami (Haramoto i Gallandt 2005; Alsaadawi i wsp. 2012; Bertholdsson i wsp. 2012; Weston i wsp. 2013). W 2005 roku zainteresowano się kwasem krotonowym, który w naturze występuje w nasionach roślin z rodziny Umbeliferae (głównie w marchwi) i jest uwalniany w czasie ich kiełkowania. Przeprowadzone badania pozwoliły stwierdzić, że ekstrakt z nasion marchwi działa fitotoksycznie na m.in. ogórka, rzeżuchę i cebulę, a substancją wykazującą takie działanie jest kwas krotonowy (Misiak i wsp. 2005).

W badaniach prowadzonych na siewkach kukurydzy rosnącej w kulturach wodnych wykazano, że kwas krotonowy ograniczył wzrost siewek kukurydzy i aktywność enzymu reduktazy azotanowej oraz spowodował wzrost zawartości chlorofilu (Demczuk i wsp. 2015). Z kolei w pracach nad współdziałaniem kwasu krotonowego z herbicydem zawierającym rimsulfuron wykazano, że modyfikuje on działanie tego środka w stosunku do siewek kukurydzy (Demczuk i wsp. 2014).

Zdolności roślin do ograniczania liczebności chwastów mogą być wykorzystane do regulacji zachwaszczenia poprzez m.in. dodatek ekstraktów z nich pozyskanych lub syntetycznych odpowiedników substancji bioaktywnych do herbicydów. Łączne zastosowanie herbicydów z substancjami o działaniu inhibitującym w stosunku do chwastów może dawać synergistyczny lub antagonistyczny efekt. Synergizm oznacza, że zniszczenie chwastów po aplikacji takiej mieszaniny jest większe niż dla każdej z substancji zastosowanej oddzielnie, co wykazano m.in. dla łącznego zastosowania wyciągów wodnych słonecznika i sorga z glifosatem (Iqbal i wsp. 2009) oraz mieszaniną jodosulfuron + mezosulfuron (Razzaq i wsp. 2012), a także wyciągu z ryżu z fenoksapropem i bromoksynilem (Khan i wsp. 2016). Dzięki temu, w obu przypadkach można było znacznie zredukować dawkę herbicydów, z zachowaniem zadowalającej efektywności chwastobójczej. Z kolei antagonizm jest zjawiskiem niekorzystnym i oznacza, że działanie mieszaniny dwóch lub więcej substancji na chwasty jest słabsze niż każdej z nich stosowanej oddzielnie.

Zakłada się, że dodatek kwasu krotonowego do niektórych herbicydów może poprawić ich działanie, co pozwala obniżyć dawkę środka chwastobójczego bez spadku jego skuteczności.
Celem badań była ocena skuteczności chwastobójczej obniżonych dawek nikosulfuronu i mieszaniny bromoksynilu z terbutylazyną z kwasem krotonowym.

\section{Materiały i metody / Materials and methods}

Doświadczenia przeprowadzono w warunkach szklarniowych w Zakładzie Herbologii i Technik Uprawy Roli Instytutu Uprawy Nawożenia i Gleboznawstwa - Państwowego Instytutu Badawczego we Wrocławiu. Doniczki wypełniono podłożem składającym się z torfu i piasku w stosunku objętościowym $2: 1$, do których wysiano nasiona chwastów na głębokość $0,5 \mathrm{~cm}$, w ilości 7 sztuk na doniczkę. Do badań wykorzystano następujące gatunki chwastów: Amaranthus retroflexus L. (AMARE), Chenopodium album L. (CHEAL), Viola arvensis Murr. (VIOAR), Matricaria inodora L. (MATIN) i Capsella bursa-pastoris L. (CAPBP). Bezpośrednio po siewie doniczki podlano i umieszczono na stołach w szklarni. Podlewano je codziennie przez cały okres prowadzenia doświadczenia.

Wykonano dwa doświadczenia nad wpływem kwasu krotonowego na skuteczność herbicydów. Dla każdego z herbicydów założono osobne doświadczenie w trzech powtórzeniach, a każdą serię powtórzono trzykrotnie. W doświadczeniu nr 1 użyto herbicyd Nikosar 060 OD (nikosulfuron), natomiast w doświadczeniu nr 2 herbicyd Kukugran 340 SE (bromoksynil + terbutylazyna), samodzielnie lub w mieszaninie z kwasem krotonowym. Dawka podstawowa (DP) dla herbicydu Nikosar 060 OD wynosiła 0,5 1/ha (nikosulfuron $30 \mathrm{~g} / \mathrm{ha}$ ), zaś dla środka Kukugran $340 \mathrm{SE}$ 1,6 1/ha (bromoksynil $144 \mathrm{~g} / \mathrm{ha}+$ terbutylazyna $400 \mathrm{~g} / \mathrm{ha}$ ). W badaniach uwzględniono następujące obiekty: 1. nieopryskiwaną kontrolę, 2. kwas krotonowy w dawce 1,80 kg/ha (KK1), 3. kwas krotonowy w dawce 3,59 kg/ha (KK2), 4. herbicyd w dawce podstawowej (100\% DP), 5. herbicyd $\mathrm{w}$ dawce $10 \% \mathrm{DP}, 6$. herbicyd $\mathrm{w}$ dawce $10 \% \mathrm{DP}+\mathrm{KK} 1$, 7. herbicyd $w$ dawce $10 \% \mathrm{DP}+\mathrm{KK} 2,8$. herbicyd $\mathrm{w}$ dawce $20 \%$ DP, 9. herbicyd w dawce 20\% DP + KK1, 10. herbicyd w dawce $20 \% \mathrm{DP}+\mathrm{KK} 2,11$. herbicyd w dawce $50 \% \mathrm{DP}$ (H50\%DP), 12.herbicydwdawce 50\%DP+KK1, 13.herbicyd w dawce $50 \% \mathrm{DP}+\mathrm{KK} 2$.

Dzień przed zabiegiem wykonano ręczną przerywkę, pozostawiając po 5 roślin w każdej doniczce. W momencie opryskiwania rośliny znajdowały się we wczesnej fazie rozwojowej, tj. 2-4 liście (BBCH 12-14), z wyjątkiem C. bursa-pastoris, który osiągnął fazę 4-6 liści (BBCH 14-16). Zabieg wykonano w komorze opryskowej „Aporo” wyposażonej w ruchomą dyszę (TeeJet XR 11003-VS), pracującą z ciśnieniem roboczym $200 \mathrm{kPa}$ i zapewniającą wydatek cieczy użytkowej 250 1/ha.

Trzy tygodnie po aplikacji środków, rośliny z każdej doniczki ścięto i zważono. Skuteczność badanych środków i ich mieszanin określono na podstawie ubytku świeżej masy 
pod wpływem ich działania w porównaniu do nieopryskiwanej kontroli. Obliczenia statystyczne wykonano na danych skuteczności chwastobójczej (średnie z trzech serii doświadczeń) wyrażonych w procentach, przekształconych według wzoru Blissa, które poddano analizie wariancji i na podstawie testu Tukeya ustalono grupy jednorodne dla herbicydu stosowanego samodzielnie oraz łącznie z kwasem krotonowym. Wyniki przedstawione w tabelach są średnimi z trzech serii każdego doświadczenia.

\section{Wyniki i dyskusja / Results and discussion}

Zastosowany w obu doświadczeniach kwas krotonowy zredukował biomasę chwastów w bardzo niewielkim stopniu (na poziomie kilku procent), przy czym najsilniej ograniczana była masa $C$. bursa-pastoris $(8-15 \%)$ (tab. 1, 2). $\mathrm{W}$ doświadczeniu z mieszaniną bromoksynil + terbutylazyna (Kukugran 340 SE) osiągnięto wysoką skuteczność (96-100\%) w niszczeniu każdego z badanych gatunków chwastów po zastosowaniu dawki podstawowej herbicydu (tab. 2). Wysoki efekt chwastobójczy wykazano również po aplikacji dawki obniżonej o 50\% w stosunku do Ch. album, $V$. arvensis, $M$. inodora, C. bursa-pastoris, natomiast $A$. retroflexus niszczony był w 71\%. Dodatek kwasu krotonowe- go do herbicydu w dawce obniżonej o 50\% nie wpłynął na stopień zniszczenia badanych gatunków chwastów. W przypadku zastosowania herbicydu w dawce zredukowanej o $80 \%$ (20\% DP) nie zanotowano różnic w zniszczeniu $A$. retroflexus, $M$. inodora, C. bursa-pastoris i $V$. arvensis pomiędzy herbicydem stosowanym samodzielnie i w mieszaninie z kwasem krotonowym (niezależnie od dawki). Zastosowanie herbicydu w powyższej dawce łącznie z kwasem krotonowym spowodowało poprawę skuteczności środka w zwalczaniu Ch. album o 17 i 21\%, odpowiednio dla wyższej i niższej dawki kwasu krotonowego. Najniższa dawka środka (10\% DP) w słabym stopniu zwalczała oceniane gatunki chwastów, z wyjątkiem C. bursa-pastoris, który był redukowany w stopniu śred$\operatorname{nim}(76 \%)$. Dodatek kwasu krotonowego do herbicydu w zróżnicowany sposób wpłynął na jego działanie, w zależności od gatunku chwastu. Gatunki A. retroflexus, C. bursa-pastoris i $V$. arvensis były w podobnym stopniu niszczone przez sam herbicyd oraz jego mieszaninę z kwasem krotonowym. Zaobserwowano natomiast korzystny wpływ kwasu krotonowego na działanie najniższej dawki środka w stosunku do Ch. album i M. inodora. Skuteczność zwalczania Ch. album po zastosowaniu mieszaniny wzrosła o 21 i 30\%, a $M$. inodora o 19 i 22\%, w zależności od dawki kwasu krotonowego.

Tabela 1. Skuteczność chwastobójcza mieszaniny bromoksynil + terbutylazyna (Kukugran 340 SE) zastosowanej samodzielnie i z dodatkiem kwasu krotonowego

Table 1. The weed control efficacy of the mixture bromoxynil + terbuthylazine (Kukugran $340 \mathrm{SE}$ ) applied alone and with crotonic acid

\begin{tabular}{|c|c|c|c|c|c|c|}
\hline \multirow{2}{*}{$\begin{array}{l}\text { Obiekty } \\
\text { Treatments }\end{array}$} & \multirow{2}{*}{$\begin{array}{c}\text { Dawki } \\
\text { Doses } \\
\text { [/ha] }\end{array}$} & \multicolumn{5}{|c|}{$\begin{array}{c}\text { Zniszczenie chwastów - Weed control } \\
{[\%]}\end{array}$} \\
\hline & & AMARE & CHEAL & VIOAR & MATIN & CAPBP \\
\hline Kwas krotonowy 1 & $1,80 \mathrm{~kg}$ & $3 \mathrm{~d}$ & $6 \mathrm{~d}$ & $5 \mathrm{~d}$ & $8 \mathrm{~d}$ & $15 \mathrm{c}$ \\
\hline Kwas krotonowy 2 & $3,59 \mathrm{~kg}$ & $7 \mathrm{~d}$ & $10 \mathrm{~d}$ & $1 \mathrm{~d}$ & $6 \mathrm{~d}$ & $11 \mathrm{c}$ \\
\hline Bromoksynil + terbutylazyna $100 \%$ DP & $144+400 \mathrm{~g}$ & 99 a & $98 \mathrm{a}$ & $100 \mathrm{a}$ & 96 a & $98 \mathrm{a}$ \\
\hline Bromoksynil + terbutylazyna $10 \%$ DP & $14,4+40 \mathrm{~g}$ & $40 \mathrm{c}$ & $26 \mathrm{~d}$ & $62 \mathrm{bc}$ & $54 \mathrm{c}$ & $76 \mathrm{~b}$ \\
\hline $\begin{array}{l}\text { Bromoksynil + terbutylazyna } 10 \% \text { DP } \\
+ \text { kwas krotonowy } 1\end{array}$ & $\begin{array}{l}14,4+40 \mathrm{~g} \\
+1,80 \mathrm{~kg}\end{array}$ & $43 \mathrm{c}$ & $47 \mathrm{c}$ & $67 \mathrm{c}$ & $73 \mathrm{~b}$ & $80 \mathrm{~b}$ \\
\hline $\begin{array}{l}\text { Bromoksynil + terbutylazyna } 10 \% \text { DP } \\
+ \text { kwas krotonowy } 2\end{array}$ & $\begin{array}{l}14,4+40 \mathrm{~g} \\
+3,59 \mathrm{~kg}\end{array}$ & $52 \mathrm{c}$ & $56 \mathrm{c}$ & $55 \mathrm{c}$ & $76 \mathrm{~b}$ & $71 \mathrm{~b}$ \\
\hline Bromoksynil + terbutylazyna $20 \%$ DP & $18,8+80 \mathrm{~g}$ & $63 \mathrm{~b}$ & $72 b$ & $73 \mathrm{~b}$ & $77 \mathrm{~b}$ & $77 \mathrm{~b}$ \\
\hline $\begin{array}{l}\text { Bromoksynil + terbutylazyna } 20 \% \text { DP } \\
+ \text { kwas krotonowy } 1\end{array}$ & $\begin{array}{l}18,8+80 \mathrm{~g} \\
+1,80 \mathrm{~kg}\end{array}$ & $74 \mathrm{~b}$ & 89 a & $69 \mathrm{~b}$ & $75 \mathrm{~b}$ & $75 b$ \\
\hline $\begin{array}{l}\text { Bromoksynil + terbutylazyna 20\% DP } \\
+ \text { kwas krotonowy } 2\end{array}$ & $\begin{array}{l}18,8+80 \mathrm{~g} \\
+3,59 \mathrm{~kg}\end{array}$ & $70 \mathrm{~b}$ & 93 a & $65 \mathrm{~b}$ & $72 \mathrm{~b}$ & $82 \mathrm{~b}$ \\
\hline Bromoksynil + terbutylazyna 50\% DP & $72+200 \mathrm{~g}$ & $71 \mathrm{~b}$ & 93 a & $87 \mathrm{a}$ & $94 \mathrm{a}$ & $89 \mathrm{a}$ \\
\hline $\begin{array}{l}\text { Bromoksynil + terbutylazyna } 50 \% \text { DP } \\
+ \text { kwas krotonowy } 1\end{array}$ & $\begin{array}{l}72+200 \mathrm{~g} \\
+1,80 \mathrm{~kg}\end{array}$ & $75 \mathrm{~b}$ & 97 a & $83 \mathrm{ab}$ & $90 \mathrm{a}$ & $94 \mathrm{a}$ \\
\hline $\begin{array}{l}\text { Bromoksynil + terbutylazyna 50\% DP } \\
+ \text { kwas krotonowy } 2\end{array}$ & $\begin{array}{l}72+200 \mathrm{~g} \\
+3,59 \mathrm{~kg}\end{array}$ & $79 \mathrm{~b}$ & $96 \mathrm{a}$ & $80 \mathrm{ab}$ & $88 \mathrm{a}$ & 97 a \\
\hline
\end{tabular}

DP - dawka podstawowa herbicydu - basic dose of herbicide

Skróty gatunków chwastów podano w rozdziale „Materiały i metody” - Weeds species abbreviations are given in the section "Materials and methods" Wartości oznaczone tą samą literą w obrębie kolumny nie różnią się istotnie - The values marked by the same letter within column do not differ significantly 
Tabela 2. Skuteczność chwastobójcza nikosulfuronu (Nikosar 060 OD) zastosowanego samodzielnie i z dodatkiem kwasu krotonowego Table 2. The weed control efficacy of nicosulfuron (Nikosar 060 OD) applied alone and with crotonic acid

\begin{tabular}{|c|c|c|c|c|c|c|}
\hline \multirow{2}{*}{$\begin{array}{l}\text { Obiekty } \\
\text { Treatments }\end{array}$} & \multirow{2}{*}{$\begin{array}{c}\text { Dawki } \\
\text { Doses } \\
{[/ \mathrm{ha}]}\end{array}$} & \multicolumn{5}{|c|}{$\begin{array}{c}\text { Zniszczenie chwastów - Weed control } \\
{[\%]}\end{array}$} \\
\hline & & AMARE & CHEAL & VIOAR & MATIN & CAPBP \\
\hline Kwas krotonowy 1 & $1,80 \mathrm{~kg}$ & $-1 \mathrm{~d}$ & $6 \mathrm{~d}$ & $-3 d$ & $-1 \mathrm{~d}$ & $9 \mathrm{~d}$ \\
\hline Kwas krotonowy 2 & $3,59 \mathrm{~kg}$ & $4 \mathrm{~d}$ & $5 \mathrm{~d}$ & $2 \mathrm{~d}$ & $6 \mathrm{~d}$ & $13 \mathrm{~d}$ \\
\hline Nikosulfuron $100 \%$ DP & $30 \mathrm{~g}$ & $98 \mathrm{a}$ & $96 \mathrm{a}$ & $97 \mathrm{a}$ & $98 \mathrm{a}$ & $97 \mathrm{a}$ \\
\hline Nikosulfuron $10 \%$ DP & $3 \mathrm{~g}$ & $75 \mathrm{~b}$ & $48 \mathrm{c}$ & $70 \mathrm{~b}$ & $61 \mathrm{~b}$ & $77 \mathrm{c}$ \\
\hline Nikosulfuron $10 \%$ DP + kwas krotonowy 1 & $3 \mathrm{~g}+1,80 \mathrm{~kg}$ & $62 \mathrm{c}$ & $77 \mathrm{~b}$ & $63 \mathrm{c}$ & $17 \mathrm{c}$ & $77 \mathrm{c}$ \\
\hline Nikosulfuron $10 \%$ DP + kwas krotonowy 2 & $3 \mathrm{~g}+3,59 \mathrm{~kg}$ & $58 \mathrm{c}$ & $84 \mathrm{~b}$ & $61 \mathrm{c}$ & $23 \mathrm{c}$ & $75 \mathrm{c}$ \\
\hline Nikosulfuron $20 \%$ DP & $6 \mathrm{~g}$ & $89 \mathrm{a}$ & $72 \mathrm{~b}$ & $86 \mathrm{a}$ & $85 \mathrm{a}$ & $84 \mathrm{~b}$ \\
\hline Nikosulfuron $20 \%$ DP + kwas krotonowy 1 & $6 \mathrm{~g}+1,80 \mathrm{~kg}$ & $75 \mathrm{~b}$ & $89 \mathrm{a}$ & $70 \mathrm{~b}$ & $68 \mathrm{~b}$ & $80 \mathrm{~b}$ \\
\hline Nikosulfuron $20 \%$ DP + kwas krotonowy 2 & $6 \mathrm{~g}+3,59 \mathrm{~kg}$ & $77 \mathrm{~b}$ & $86 \mathrm{a}$ & $66 \mathrm{~b}$ & $76 \mathrm{~b}$ & $85 \mathrm{~b}$ \\
\hline Nikosulfuron $50 \%$ DP & $15 \mathrm{~g}$ & $94 \mathrm{a}$ & $90 \mathrm{a}$ & $95 \mathrm{a}$ & $92 \mathrm{a}$ & $95 \mathrm{a}$ \\
\hline Nikosulfuron 50\% DP + kwas krotonowy 1 & $15 \mathrm{~g}+1,80 \mathrm{~kg}$ & $95 \mathrm{a}$ & $95 \mathrm{a}$ & 96 a & $96 \mathrm{a}$ & $94 \mathrm{a}$ \\
\hline Nikosulfuron 50\% DP + kwas krotonowy 2 & $15 \mathrm{~g}+3,59 \mathrm{~kg}$ & $96 \mathrm{a}$ & $92 \mathrm{a}$ & $92 \mathrm{a}$ & $89 \mathrm{a}$ & $95 \mathrm{a}$ \\
\hline
\end{tabular}

DP - dawka podstawowa herbicydu - basic dose of herbicide

Skróty gatunków chwastów podano w rozdziale „Materiały i metody” - Weeds species abbreviations are given in the section "Materials and methods” Wartości oznaczone tą samą literą w obrębie kolumny nie różnią się istotnie - The values marked by the same letter within column do not differ significantly

W drugim doświadczeniu, dawka podstawowa nikosulfuronu (Nikosar 060 OD) z bardzo dobrym efektem (97-99\%) ograniczała biomasę każdego z ocenianych gatunków chwastów (tab. 3). Równie skuteczna była dawka obniżona o połowę ( $50 \%$ DP), niezależnie od tego czy herbicyd zastosowano samodzielnie, czy w mieszaninie z kwasem krotonowym. Nikosulfuron zastosowany samodzielnie w dawkach obniżonych o 80 i $90 \%$ (20\% DP i $10 \%$ DP) oraz w mieszaninie $\mathrm{z}$ kwasem krotonowym w obu badanych dawkach w podobnym zakresie niszczył C. bursa-pastoris. Dodatni wpływ kwasu krotonowego na efektywność nikosulfuronu w dawkach 20\% DP i 10\% DP odnotowano w przypadku Ch. album. Nikosulfuron w dawce 20\% DP zwalczał ten gatunek w 72\%, natomiast po dodaniu kwasu krotonowego osiągnięto skuteczność na poziomie $86-89 \%$. Dawka najniższa herbicydu (10\% DP) była efektywna na poziomie $48 \%$, zaś dodatek kwasu krotonowego przyczynił się do wzrostu skuteczności do 77 i 84\% (odpowiednio dla niższej i wyższej dawki kwasu krotonowego). Negatywny wpływ kwasu krotonowego na działanie herbicydu w dawkach niższych (10\% DP i 20\% DP) stwierdzono dla pozostałych trzech gatunków chwastów, tj. A. retroflexus, $M$. inodora i $V$. arvensis. Największy spadek skuteczności nikosulfuronu na skutek łącznej aplikacji z kwasem krotonowym (wynoszący 38-44\%) zanotowano po zastosowaniu środka w dawce najniższej ( $10 \%$ DP) w stosunku do $M$. inodora. W pozostałych przypadkach obniżenie skuteczności nie przekraczało $20 \%$.

Działanie inhibitujące kwasu krotonowego w stosunku do roślin i możliwości jego wykorzystania do ogranicza- nia dawki herbicydu jest jak dotychczas zagadnieniem poznanym w znikomym stopniu. Dotychczasowe prace prowadzone były w warunkach laboratoryjnych, na szalkach Petriego lub w kulturach wodnych. W tych ostatnich testowano również działanie kwasu krotonowego w połączeniu z herbicydami zawierającymi rimsulfuron i glufosynat. Stwierdzono znaczący wpływ tej substancji w znoszeniu szkodliwego wpływu rimsulfuronu na siewki kukurydzy (Demczuk i wsp. 2014). Natomiast w przypadku połączenia z glufosynatem nastąpiło zahamowanie wzrostu siewek ogórka w znacznie większym stopniu niż każda z substancji oddzielnie oraz zmodyfikowało poziom białka ogólnego w organach. Wyniki tych prac wskazują na bioaktywne działanie kwasu krotonowego oraz współdziałanie $\mathrm{z}$ herbicydami w stosunku do roślin, co dało podstawę do wykorzystania tej substancji w badaniach aplikacyjnych.

Przedstawione w niniejszej pracy rezultaty badań dały zróżnicowane efekty, w zależności od rodzaju środka, jego dawki oraz gatunku chwastu. Wpływ kwasu krotonowego na skuteczność chwastobójczą herbicydów widoczny był dopiero dla bardzo niskich dawek herbicydów, tj. obniżonych o 80 i $90 \%$. W przypadku aplikacji dawki obniżonej o 50\% nie stwierdzono istotnych różnic pomiędzy środkami stosowanymi samodzielnie a w mieszaninie $\mathrm{z}$ kwasem krotonowym. Efektywność tej dawki w warunkach prowadzenia doświadczenia (warunki szklarniowe) była zbyt wysoka, zbliżona do dawki podstawowej. Nie wykazano ponadto zróżnicowania $\mathrm{w}$ działaniu badanych mieszanin w zależności od dawki kwasu krotonowego, jakkolwiek różnica w wysokości dawek była duża. Może być to podstawą 
do zastosowania w dalszych badaniach znacznie niższych dawek tej substancji niż użyte obecnie, pod warunkiem, że dawki te będą skuteczne pod względem chwastobójczym.

Dodatek kwasu krotonowego do badanych herbicydów w zróżnicowany sposób wpłynął na efekt chwastobójczy, w zależności od zwalczanego gatunku chwastu. Kwas krotonowy nie zmienił działania badanych środków w stosunku do C. bursa-pastoris, natomiast wyraźnie poprawił w stosunku do Ch. album. Nawet jeśli w przypadku mieszaniny każdego środków z kwasem krotonowym w dawce najniższej (10\% DP) nie osiągnięto wysokiej skuteczności, jednak nastąpiła wyraźna poprawa w redukcji biomasy tego gatunku. Świadczy to o dużej wrażliwości Ch. album na kombinację badanych środków chwastobójczych z kwasem krotonowym. Przeprowadzone badania wykazały również antagonistyczne działanie kwasu krotonowego z herbicydem Nikosar 060 OD, który stosowany w mieszaninie słabiej niszczył $A$. retroflexus, $V$. arvensis, $M$. inodora w porównaniu z samodzielną aplikacją. W doświadczeniach polowych z zastosowaniem kombinacji ekstraktów wodnych z różnych roślin uprawnych (m.in. sorga, słonecznika, rzepaku) z herbicydami w obniżonych dawkach uzyskiwano znacznie lepsze efekty, na poziomie dawki zalecanej (Khaliq i wsp. 2012; Iqbal i wsp. 2020). Jednak w takich przypadkach nie był znany skład ekstraktów, ani dawka występujących w nich substancji bioaktywnych, co może skutkować zróżnicowanym efektem chwastobójczym w kolejnych sezonach wegetacyjnych.

\section{Wnioski / Conclusions}

1. Kwas krotonowy w zróżnicowany sposób wpływał na efektywność herbicydów Kukugran 340 SE i Nikosar 060 OD stosowanych w obniżonych dawkach, w zależności od rodzaju środka, wysokości dawki oraz gatunku chwastu. Wpływ ten zaobserwowano tylko dla dawek najniższych, tj. obniżonych o 80 i 90\%.

2. Kwas krotonowy nie wpłynął na skuteczność badanych herbicydów w stosunku do C. bursa-pastoris.

3. Dodatek kwasu krotonowego poprawił działanie obu badanych herbicydów w dawkach najniższych w stosunku do Ch. album oraz środka Kukugran 340 SE w dawce obniżonej o 90\% w stosunku do M. inodora.

4. Niekorzystny wpływ kwasu krotonowego na skuteczność chwastobójczą stwierdzono jedynie dla herbicydu Nikosar 060 OD stosowanego na $V$. arvensis, $M$. inodora i $A$. retroflexus.

5. Nie zaobserwowano różnic w skuteczności badanych mieszanin w zależności od wysokości dawki kwasu krotonowego.

Opracowanie wykonano w ramach programu statutowego 2.43 Instytutu Uprawy Nawożenia i Gleboznawstwa - Państwowego Instytutu Badawczego.

\section{Literatura / References}

Alsaadawi I.S., Sarbout A.K., Al-Shamma L.M. 2012. Differential allelopathic potential of sunflower (Helianthus annus L.) genotypes on weeds and wheat (Triticum aestivum L.) crop. Archives of Agronomy and Soil Science 58 (10): 1139-1148. DOI: $10.1080 / 03650340.2011 .570335$

Bertholdsson N.-O., Andersson S.C., Merker A. 2012. Allelopathic potential of Triticum spp., Secale spp. and Triticosecale spp. and use of chromosome substitutions and tranlocations to improve weed suppression ability in winter wheat. Plant Breeding 131 (1): 75-80. DOI: $10.1111 / j .1439-0523.2011 .01895 . x$

Demczuk A., Grzyś E., Majewska E., Sacała E. 2015. Oddziaływanie kwasu krotonowego na siewki kukurydzy. [Effect of crotonic acid on maize seedlings]. Przemysł Chemiczny 91 (5): 729-732.

Demczuk A., Grzyś E., Sacała E. 2014. The combined action of allelochemicals and the sulfonylurea herbicide on maize seedlings. Proceedings of 7-th World Congress of Allelopathy, 28.07-01.08.2014, Vigo, Spain, s. 148.

Haramoto E.R., Gallandt E.R. 2005. Brassica cover cropping: I. Effects on weed and crop establishment. Weed Science 53 (5): $695-701$. DOI: $10.2307 / 4047040$

Iqbal J., Cheema Z.A., Mushtaq M.N. 2009. Allelopathic crop water extracts reduce the herbicide dose for weed control in cotton (Gossypium hirsutum). International Journal of Agriculture and Biology 11 (4): 360-366.

Iqbal N., Khaliq A., Cheema Z.A. 2020. Weed control through allelopathic crop water extracts and $S$-metolachlor in cotton. Information Processing in Agriculture 7 (1): 165-172. DOI: 10.1016/j.inpa.2019.03.006

Khaliq A., Matloob A., Tanweer A., Khan M.B. 2012. Naturally occurring phytotoxins in allelopathic plants help reduce herbicide dose in wheat. Natural Product Research 26 (12): 1156-1160. DOI: 10.1080/14786419.2011.562204

Khan M.A., Afridi R.A., Hashim S., Khattak A.M., Ahmad Z., Wahid F., Chauhan B.S. 2016. Integrated effect of allelochemicals and herbicides on weed suppression and soil microbial activity in wheat (Triticum aestivum L.). Crop Protection 90: 34-39. DOI: 10.1016/j. cropro.2016.08.018

Misiak I.J., Wieczorek P.P., Kafarski P. 2005. Crotonic acid as a bioactive factor in carrot seeds (Daucus carota L.). Phytochemistry 66 (12): 1485-1491. DOI: 10.1016/j.phytochem.2005.04.005

Razzaq A., Cheema Z.A., Jabran K., Hussain M., Farooq M., Zafar M. 2012. Reduced herbicide doses used together with allelopathic sorghum and sunflower water extracts for weed control in wheat. Journal of Plant Protection Research 52 (2): 281-285. DOI: 10.2478/ v10045-012-0045-0

Weston L.A., Alsaadawi I.S., Baerson S.R. 2013. Sorghum allelopathy - from ecosystem to molecule. Journal of Chemical Ecology 39: 142-153. DOI: 10.1007/s10886-013-0245-8 